\title{
Analisis Perbandingan Efisiensi Penyaluran Listrik Antara Penghantar ACSR dan ACCC pada Sistem Transmisi 150kV
}

\author{
Oktaria Handayani ${ }^{1}$; Tasdik Darmana ${ }^{2}$; Christine Widyastuti ${ }^{3}$ \\ 1,2, ${ }^{3}$ Teknik Elektro, Sekolah Tinggi Teknik PLN \\ 1oktaria@sttpln.ac.id \\ ${ }^{2}$ tdarmana@gmail.com \\ ${ }^{3}$ christine.widyastuti@sttpln.ac.id
}

\begin{abstract}
Electricity need in Indonesia continues to increase in accordance with the rate of recovery of the economy and industry and the increase in population. The transmission line transmits electricity from the power plant to the load center via the High Voltage transmission lines (SUTT) or Extra High Voltage Transmissio lines (SUTET), because the long distance causes power losses. The condition before the reconducting of Tebing Tinggi - Kuala Tanjung transmission uses ACSR conductor types and after the reconducting has been replaced by the ACCC, where ACCC has 2 times the current trying of the type of ACSR. In this study, we will examine and analyze the magnitude of the power losses and the efficiency of the distribution of the two types of ACSR and ACCC supply channels with a case study of the $150 \mathrm{kV}$ transmission system Tebing Tinggi - Kuala Tanjung which has a distance of $71.5 \mathrm{~km}$. From the calculation results obtained, after the reconducting process using the conductor the ACCC was able to reduce power losses and increase efficiency by $1.35 \%$.
\end{abstract}

Keywords: Power loss, conductor capacity, reconductoring

\begin{abstract}
ABSTRAK
Kebutuhan tenaga listrik di Indonesia terus meningkat sesuai dengan laju pertembuhan ekonomi dan industri serta bertambahnya penduduk. Saluran transmisi menyalurkan tenaga listrik dari pusat pembangkit sampai ke pusat beban melalui Saluran Udara Tegangan tinggi (SUTT) atau Saluran Udara Tegangan Ekstra Tinggi (SUTET), oleh karena jarak yang jauh tersebut menyebabkan adanya rugi - rugi daya. Kondisi sebelum rekonduktoring transmisi Tebing Tinggi - Kuala Tanjung menggunakan jenis penghantar ACSR dan setelah rekonduktoring diganti menjadi penghantar ACCC, dimana ACCC memiliki current trying 2 kali lipat dari penghantar jenis ACSR. Pada Penelitian ini akan mengkaji dan menganalisis berapakah besarnya rugi - rugi daya serta efisiensi penyaluran dari kedua jenis penghantar yairu ACSR dan ACCC dengan studi kasus sistem transmisi 150 kV Tebing Tinggi - Kuala Tanjung yang memiliki jarak 71,5 km. Dari hasil perhitungan didapatkan, setelah proses rekonduktoring edngan menggunakan penghantar ACCC mampu menurunkan rugi - rugi daya dan meningkatkan efisiensi sebesar 1,35\%.
\end{abstract}

Kata kunci: Rugi-rugi daya, kapasitas konduktor, rekonduktoring 


\section{PENDAHULUAN}

Dalam sistem penyaluran tenaga listrik umumnya dikenal 3 aspek yang penting yaitu pembangkit, transmisi dan distribusi. Listrik yang dihasilkan oleh pembangkit disalurkan melalui system transmisi dimana system transmisi bisa terdiri dari Saluran Udara Tegangan Ekstra Tinggi maupun Saluran Udara Tegangan tinggi ke system distribusi untuk disalurkan ke pusat beban. Jarak antara pembangkit dan pusat beban yang letaknya berjauhan tersebut menyebabkan adanya factor rugi - rugi sitem penyaluran listrik.

Penggunaan jenis konduktor merupakan salah satu cara untuk menurunkan rugi - rugi listrik dalam proses penyalurannya. Konduktor dengan jenis ACCC dikenal lebih handal dalam menyalurkan listrik dari pada jenis konduktor ACSR. Sebagai bahan studi kasus akan dibahas jaringan transmisi Tebing Tinggi - Kuala Tanjung dimana kondisi keandalan kapasitas penghantar Tebing Tinggi Kuala Tanjung memang memerlukan rekonduktoring karena sering terjadi anomaly pada penghantar yang mengakoibatkan jika salah satu line/ jaringan mengalami pemadaman, maka jaringan yang lain akan menopang beban dari jaringan yang padam. Pada penelitian ini akan dibahas berapakah penurunan rugi - rugi daya dan efisiensi penyaluran daya listrik antara konduktor ACSR (kondisi sebelum rekonduktoring) dengan konduktor ACCC (setelah rekonduktoring).

\section{METODE / PERANCANGAN PENELITIAN}

Parameter - parameter yang diperhitungkan terdiri dari

\section{Analisa Rugi Daya}

Resistansi total

$$
R_{\text {total }}=R \times l
$$

Reaktansi Total

$$
X_{\text {total }}=X L \times l
$$

Impedansi Total

$$
\text { Nilai } \theta=\arctan \left(\frac{X}{R}\right)
$$

\section{Faktor Daya}

Untuk mencari faktor daya terlebih dahulu kita mencari besar daya semu (S)

$$
S=\sqrt{P_{r}^{2}+Q^{2}}
$$

Maka untuk mencari faktor daya yaitu:

$$
\cos \varphi=\frac{P}{S}
$$




\section{Tegangan Pengiriman}

Untuk mencari besar jatuh tegangannya, faktor kapasitansi dapat diabaikan dalam perhitungan. Persamaan yang digunakan sebagai berikut:

$$
\begin{aligned}
& \left|I_{s}\right|=\left|I_{R}\right| \\
& V_{s}=\left|V_{R}\right|+\left|I_{R}\right||Z|
\end{aligned}
$$

Sebelum mencari jatuh tegangan, kita harus mencari dulu nilai sudut $\theta$.

Daya pengiriman dapat dicari seperti berikut ini:

$$
\begin{aligned}
& P_{s}=P_{R}+P_{\text {rugi-rugi }} \\
& \Delta P=P_{s}-P_{R}
\end{aligned}
$$

\section{Jatuh tegangan (regulasi tegangan)}

Dari hasil perhitungan di atas, maka diketahui hasil $V_{S}$ dan $V_{R}$ sehingga didapat regulasi tegangannya:

$$
\Delta V=\frac{V_{s}-V_{R}}{V_{S}} \times 100 \%
$$

\section{Rugi Korona}

Untuk mencari rugi korona terlebih dahulu mencari kepadatan udara relatif dan gradien tegangan pada permukaan kawat yaitu sebagai berikut:

\section{Kepadatan udara relative}

$$
\delta=\frac{0,386 b}{272+t^{o}}
$$

Gradien tegangan pada permukaan kawat untuk saluran transmisi 3 fasa:

$$
E_{g}=\frac{0,4343 E}{r \log _{10}\left(\frac{D}{r}\right)}(\mathrm{kV} / \mathrm{cm})
$$

Setelah diketahui hasil dari nilai kepadatan udara relatif dan gradien tegangan permukaan kawat, maka dapat dicari besar rugi - rugi daya korona sebagai berikut:

$$
P=\frac{A}{\delta}(f+25) r^{2}\left(E_{g}-m \delta E_{g o}^{\prime}\right) 10^{-2}
$$

Dimana:

$\mathrm{E}_{\mathrm{go}}^{\prime} \quad=21,1 \mathrm{kV} / \mathrm{cm}$ Gradien tegangan permukaan kawat

A $\quad=0,448$ untuk kawat padat dan 0,375 untuk kawat lilit

$\mathrm{m} \quad=\mathrm{m}_{\mathrm{o}} \times \mathrm{m}_{1}=0,83 \times 1,0=0,83$ 
Setelah diketahui besar rugi korona, maka dapat dicari besar rugi korona total pada penghantar sebagai berikut:

$$
P_{\text {koronatotal }}=P \times L
$$

\section{Rugi daya Total}

Rugi daya total adalah penjumlahan dari rugi daya resistan dengannjumlah rugi korona total. Maka rugi daya total dapat dicari sebagai berikut:

$$
P_{\text {rugi }}=\Delta P+P_{\text {koronatotal }}
$$

\section{Daya pengiriman}

Untuk mencari daya pengiriman yaitu jumlah dari daya penerimaan dengan jumlah dari rugi daya total sebagai berikut:

$$
P_{\text {STotal }}=P_{r}+P_{\text {rugi }}
$$

\section{Efisiensi transmisi}

$$
\eta=\frac{P_{r}}{P_{\text {sTotal }}} \times 100 \%
$$

Kerugian korona dalam persen dari rugi daya total adalah:

$$
P=\frac{P_{\text {koronatotal }}}{\text { Rugi daya total }} \times 100 \%
$$

Metode Penelitian yang digunakan terdiri dari:

1. Teknik Pengumpulan data

Metode pengumpulan data merupakan strategi yang ditempuh untuk mengambil data lapangan

2. Studi wawancara

Tahap ini dilakukan untuk mengetahui kondisi atau permasalah lebih detail dari sisi lapangan, sebab - sebab yang mempengaruhi masalah berdasarkan nara sumber lapangan.

3. Studi Literatur

Tahapan ini dilakukan dengan cara mempelajari teori - teori yang mendukung pemecahan masalah baik dari jurnal, buku maupun penelitian yang sejenis.

4. Teknik Analisis

Analisis merupakan tahap selanjutnya untuk pengolahan data. Data yang diperoleh dari PT PLN P3B Sumatera di analisis menggunakan rumus - rumus yang sesuai dengan teori. Dalam saluran transmisi terdapat beberapa parameter diantaranya resistansi dan induktansi serta kapasitansi. Adapun variabel - variabel yang masuk dalam pengamatan berupa :
a. Rugi - rugi daya
b. Regulasi tegangan
c. Efisiensi saluran 
3. HASIL DAN PEMBAHASAN

Data saluran transmisi $150 \mathrm{kV}$ Tebing Tinggi - Kuala Tanjung sebelum rekonduktoring

Tabel 1. Data Saluran Transmisi Tebing Tinggi - Kuala Tanjung sebelum dan setelah

\begin{tabular}{|l|c|c|}
\hline \multicolumn{1}{|c|}{ Parameter } & Sebelum & Setelah \\
\hline R (Resistan per fasa) $(\mathrm{Ohm} / \mathrm{KM})$ & 0,12745 & 0,09774 \\
\hline XL (Reaktansi per fasa) $(\mathrm{Ohm} / \mathrm{KM})$ & 0,42397 & 0,40054 \\
\hline 1 (Jarak saluran) $(\mathrm{KM})$ & 71,5 & 71,5 \\
\hline A (Luas Penampang) $\left(\mathrm{mm}^{2}\right)$ & 240 & 310 \\
\hline Pr (Daya penerima) $(\mathrm{MW})$ & 96 & 110 \\
\hline Q (Daya reaktif) (MVAR) & 30 & 25 \\
\hline I (Arus line) $($ Ampere) & 410 & 420 \\
\hline Vr (Tegangan penerimaan) $($ Volt) & 143 & 144 \\
\hline r (Jari- jari konduktor) $(\mathrm{cm})$ & 0,87 & 0,99 \\
\hline D $($ Jarak Ekivalen antar kawat) $(\mathrm{M})$ & 2,5 & 2,5 \\
\hline $\mathrm{b}$ (Tekanan udara) $(\mathrm{mmHg})$ & 757,187 & 757,187 \\
\hline E (Tegangan fasa) $($ Volt) & 143 & 144 \\
\hline T (Suhu udara rata - rata) $\left({ }^{\circ} \mathrm{C}\right)$ & 31 & 31 \\
\hline F (Frekuensi) $(\mathrm{Hz})$ & 50 & 50 \\
\hline
\end{tabular}

\section{Analisa Rugi Daya}

Resistansi total

$$
R_{\text {total }}=R \times l \quad=0,12745 \Omega / \mathrm{km} \times 71,5 \mathrm{~km}=9,112675 \Omega
$$

Reaktansi Total

$$
X_{\text {total }}=X L \times l=0,42397 \Omega / \mathrm{km} \times 71,5 \mathrm{~km}=30,313855 \Omega
$$

Impedansi Total

$$
\begin{aligned}
& \text { Nilai } \theta=\arctan \left(\frac{X}{R}\right)=\arctan \left(\frac{30,313855}{9,112675}\right)=\angle 73,263 \\
& r=\sqrt{R^{2}+X^{2}}=\sqrt{9,112675^{2}+30,313855^{2}}=31,6539 \Omega
\end{aligned}
$$

Maka didapat nilai Z:

$$
Z=r \angle \theta=31,6539 \angle 73,263 \boldsymbol{\Omega}
$$

\section{Faktor Daya}

Dari data diketahui nilai daya penerimaan sebesar $96 \mathrm{MW}$ dan daya reaktif sebear $30 \mathrm{MVAR}$, maka terlebih dahulu kita mencari besar daya semu (S)

$P_{r}=96 M W$

$Q=30 M V A R$

$S=\sqrt{P_{r}^{2}+Q^{2}}=\sqrt{96^{2}+30^{2}}=100,57 M V A$ 
Maka untuk mencari faktor daya yaitu:

$\cos \varphi=\frac{P}{S}=\frac{96}{100,57}=0,95$

\section{Tegangan Pengiriman}

Saluran transmisi Tebing Tinggi - Kuala Tanjung berjarak 71,5 km, maka dapat disimpulkan bahwa saluran ini merupakan saluran jarak pendek. Untuk mencari besar jatuh tegangannya, faktor kapasitansi dapat diabaikan dalam perhitungan. Persamaan yang digunakan sebagai berikut:

$$
\begin{aligned}
& \left|I_{s}\right|=\left|I_{R}\right| \\
& V_{s}=\left|V_{R}\right|+\left|I_{R}\right| Z \mid
\end{aligned}
$$

Sebelum mencari jatuh tegangan, kita harus mencari dulu nilai sudut $\theta$.

Diketahui faktor daya $(\cos \varphi=0,95)$, maka untuk mencari nilai sudut $\theta$ dengan cara:

$\theta=\arccos \varphi=\arccos 0,95=\angle 18,1948$

Dimana $\theta=\angle V-\angle I$, maka $\angle V$ sebagai referensi, sehingga

$$
\begin{aligned}
& \angle I=\angle V-\theta \\
& \angle I=0-18,1948 \\
& \angle I=-18,1948
\end{aligned}
$$

Selanjutnya mencari tegangan pengiriman $V_{r}$ dimana $I_{R}=410 A=0,41 \mathrm{kA}$ dan $V_{R}=143 \mathrm{kV}$

$$
\begin{aligned}
& V_{s}=\left|V_{R}\right|+\left|I_{R}\right||Z| \\
& V_{s}=143 \angle 0+(0,41 \angle-18,1948 \times 31,6539 \angle 73,263)=150,811 \angle 4,0442 k \mathrm{kV}
\end{aligned}
$$

Daya pengiriman dapat dicari seperti berikut ini:

$$
\begin{aligned}
& P_{s}=P_{R}+P_{\text {rugi-rugi }}=96 \times 10^{6}+495552=100,59 \mathrm{MW} \\
& \Delta P=P_{s}-P_{R}=100,59-96 \times 10^{6}=4.595 .532 \mathrm{Watt}
\end{aligned}
$$

\section{Jatuh tegangan (regulasi tegangan)}

Dari hasil perhitungan di atas, maka diketahui hasil $V_{S}$ dan $V_{R}$ sehingga didapat regulasi tegangannya:

$$
\begin{aligned}
& \Delta V=\frac{V_{s}-V_{R}}{V_{S}} \times 100 \%=\frac{150,811-143.000}{150,811} \times 100 \%=5,17 \% \\
& P_{r u g i}=3 \times I^{2} \times R=3 \times 410^{2} \times 9,112675=4.595 .552 \mathrm{Watt}
\end{aligned}
$$




\section{Rugi Korona}

Untuk mencari rugi korona terlebih dahulu mencari kepadatan udara relatif dan gradien tegangan pada permukaan kawat yaitu sebagai berikut:

\section{Kepadatan udara relatif}

Untuk data yang digunakan yaitu tekanan udara rata-rata (b) di daerah Tebing Tinggi dan Kuala Tanjung pada 30 Agustus 2016 jam $13.00 \mathrm{WIB}$ sebesar $757,187 \mathrm{mmHg}$ dan suhu udara rata - rata $\left(\mathrm{t}^{\circ}\right)$ sebesar $31^{\circ} \mathrm{C}$.

$$
\delta=\frac{0,386 b}{272+t^{\circ}}=\frac{0,386 \times 757,187}{272+31}=0,9614
$$

Gradien tegangan pada permukaan kawat untuk saluran transmisi 3 fasa:

$$
E_{g}=\frac{0,4343 E}{r \log _{10}\left(\frac{D}{r}\right)}(\mathrm{kV} / \mathrm{cm})=\frac{0,4343 \times 143}{r \log _{10}\left(\frac{250}{0,87}\right)}=29,0369 \mathrm{kV} / \mathrm{cm}
$$

Setelah diketahui hasil dari nilai kepadatan udara relatif dan gradien tegangan permukaan kawat, maka dapat dicari besar rugi - rugi daya korona sebagai berikut:

$$
P=\frac{A}{\delta}(f+25) r^{2}\left(E_{g}-m \delta E^{\prime}{ }_{g o}\right) 10^{-2}
$$

Dimana:

$\mathrm{E}_{\text {go }} \quad=21,1 \mathrm{kV} / \mathrm{cm}$ Gradien tegangan permukaan kawat

A $\quad=0,448$ untuk kawat padat dan 0,375 untuk kawat lilit

$\mathrm{m} \quad=\mathrm{m}_{\mathrm{o}} \times \mathrm{m}_{1}=0,83 \times 1,0=0,83$

maka besar rugi korona adalah:

$$
\begin{aligned}
P & =\frac{0,375}{0,9614}(50+25) 0,87^{2}(29,0369-0,83 \times 0,9614 \times 21,1) 10^{-2}=2,701364 \mathrm{~kW} / \mathrm{km} \\
& =2.701,3649 \mathrm{~W} / \mathrm{km}
\end{aligned}
$$

Setelah diketahui besar rugi korona, maka dapat dicari besar rugi korona total pada penghantar sebagai berikut:

$$
P_{\text {koronatotal }}=P \times L=2.701,3649 \mathrm{~W} / \mathrm{km} \times 71,5=193.147,5908 \mathrm{~W}
$$

\section{Rugi daya Total}

Rugi daya total adalah penjumlahan dari rugi daya resistan dengannjumlah rugi korona total. Maka rugi daya total dapat dicari sebagai berikut:

$$
P_{\text {rugi }}=\Delta P+P_{\text {koronatotal }}=4.595 .552+193.147,5908=4,78 \mathrm{MW}
$$




\section{Daya pengiriman}

Untuk mencari daya pengiriman yaitu jumlah dari daya penerimaan dengan jumlah dari rugi daya total sebagai berikut:

$$
P_{\text {STotal }}=P_{r}+P_{\text {rugi }}=96.000 .000+4.788 .669,593=100,78 \mathrm{MW}
$$

\section{Efisiensi transmisi}

$$
\eta=\frac{P_{r}}{P_{\text {sTotal }}} \times 100 \%=\frac{96.000 .000}{100.788 .669,6} \times 100 \%=95,24 \%
$$

Jatuh tegangan yang terjadi pada jam 13.00 WIB tergolong besar yaitu 5,17\%. Hal ini disebabkan karena jumlah arus yang mengalir sangat besar yaitu 410 A sehingga besar nilai resistan pada kawat penghantar juga besar.

Kerugian korona dalam persen dari rugi daya total adalah:

$$
P=\frac{P_{\text {koronatotal }}}{\text { Rugi daya total }} \times 100 \%=\frac{193.147,5908}{4.788 .669,593} \times 100 \%=4,04 \%
$$

Hasil perhitungan rugi - rugi daya pada transmisi $150 \mathrm{kV}$ Tebing Tinggi - Kuala Tanjung sebelum pengerjaan rekonduktoring menunjukan nilai lebih kecil dari rugi - rugi daya setelah pekerjaan rekonduktoring $(95,24 \%<96,59 \%)$ atau mengalami kenaikan sebesar 1,35\% dengan mengganti konduktor ACSR 1x240 mm² dengan menggunakan konduktor ACCC HCLS 1x310 mm².

Tabel 2. Perbandingan rugi-rugi daya antar konduktor jenis ACSR dan ACCC

\begin{tabular}{|l|l|l|l|l|l|l|}
\hline Saluran & \multicolumn{1}{|c|}{ Kondisi } & $\begin{array}{c}\text { Rugi daya } \\
\text { resistan } \\
\text { (Watt) }\end{array}$ & $\begin{array}{l}\text { Rugi korona } \\
\text { (Watt) }\end{array}$ & $\% \mathrm{~V}$ & $\begin{array}{c}\text { Rugi Daya } \\
\text { total (Watt) }\end{array}$ & $\begin{array}{c}\text { Efisiensi } \\
\text { saluran (\%) }\end{array}$ \\
\hline $\begin{array}{l}\text { Tebing } \\
\text { Tinggi }\end{array}$ & $\begin{array}{l}\text { Sebelum } \\
\text { Kuala } \\
\text { Tanjung }\end{array}$ & 4.595 .522 & 193.147 & $5,17 \%$ & 4.788 .669 & $95,24 \%$ \\
\cline { 2 - 7 } & $\begin{array}{l}\text { Setelah } \\
\text { (ACCC) }\end{array}$ & 3.698 .266 & 181.263 & $4,10 \%$ & 3.879 .530 & $96,59 \%$ \\
\hline
\end{tabular}

\section{KESIMPULAN}

Berdasarkan hasil penelitian dan pembahsan, maka diperoleh kesimpulan salah satu upaya yang dapat dilakukan untuk mengurangi rugi daya yaitu proses rekonduktoring dimana proses tersebut dilakukan dengan cara mengganti jenis konduktor, seperti yang terdapat pada transmisi $150 \mathrm{kV}$ Tebing Tinggi - Kuala Tanjung. Dengan mengganti konduktor jenis ACSR ke konduktor jenis ACCC, mampu menurunkan rugi - rugi daya dan meningkatkan efisiensi sebesar $1,35 \%$.

\section{DAFTAR PUSTAKA}

[1] Zuhal, "Dasar Teknik Tenaga Listrik Dan Elektronika Daya", PT Gramedia, Jakarta, 1998

[2] Michael Liwschitz - Garik "D-c and Ac Machines Based On Fundmental Laws", D. Van Nostrand Company, Inc, 1952 
[3] Aris Munandar. A. Dan Kuwahara. S. Buku pegangan Teknik Tenaga Listrik. Jakarta: Erlangga, 1993

[4] Kadir, Abdul. Transmisi Tenaga Listrik. Jakarta : Universita Indonesia - Press, 1988

[5] Stevenson, William D, Jr. Analisis Sistem Tenaga Listrik. Jakarta : Erlangga, 1984 